\title{
Comparing silo filler disease with farmer's lung disease
}

\author{
Clyde Schultz* \\ Department of Biology, University of Calgary, Calgary, Alberta, Canada
}

\begin{abstract}
Farmer's Lung and Silo Filler's Disease are syndromes long associated with agricultural workers worldwide. The symptomology, including route of inoculation for these diseases are similar, as is the target organ (lung) but the disease causing agents are vastly different, as is how the human body responds to the antigens themselves. Farmer's Lung is caused by mold and Silo Filler's Disease is caused essentially by gas poisoning. Both may be fatal, and both are preventable largely by education of the conditions with which farmers work, including certain straightforward precautions. Following precautions such as masking, allowing for farm products such as hay to dry during the wet seasons and using ventilation in at risk facilities leads to greater protection for the agricultural worker.
\end{abstract}

\section{Disease states}

Regardless of how one defines climate change there is increasing awareness that this condition is caused by pollution, and generalized disease states on a global scale and on a more individualized level, respiratory disease can occur. These effects may not be recognized immediately but over time and with increased opportunities for exposure, pollutants regardless of their source, which include a range from carbon monoxide released into the atmosphere to nitrogen gas buildup in silos found on farms, can and do progress to immunologic disorders or infection. The portal of entry and target organ is often the lung. While mortality due to infectious disease has decreased, respiratory related infections still remain a major problem. In agricultural areas, nitrogen dioxide buildup can impair an individual's immune response and working with farm products which may occur during hay making season can lead to infections.

Lung disease in the farming community in the United States and around the world is often underreported or ignored. This is due to the nature of the work and the natural self-reliance of the farm managers and workers. Farmer's Lung (FL) and Silo Filler's Disease (SF) have similar symptomology but vastly different etiologic agents. Silo Filler's Disease is a condition that has been long associated with farm laborers. The condition was first described, but not named in the 1800's [1]. The syndrome is caused by exposure to nitrous dioxide. This commonly occurs in unventilated or under-ventilated grain silos [2,3]. Nitrogen dioxide is produced from the oxidation of plants or from nitrogen rich soil. Nitrogen gas will accumulate in closed silos within a short time (hours) of the silo being filled. High concentrations are reached within a few days and will dissipate at a slower rate (weeks) upon ventilation. In the early stages of exposure, there is lung irritation with symptoms including pulmonary edema post exposure followed by what may appear to be a brief recovery and then a relapse to acute bronchilolitis [4-8]. The nitrogen dioxide will accumulate first at the top of the poorly ventilated silos (200 - $2000 \mathrm{ppm}$ within 1-2 days) and when inhaled by humans or other animals the reaction of the $\mathrm{NO}_{2}$ with water results in nitrous acid, causing damage to the airways, or potentially any other surface that was exposed to $\mathrm{NO}_{2}$ [9-11]. Pulmonary edema may be found if high concentrations of gas are inhaled during normal breathing and work related to silo operations. In lower concentrations exudate and bronchia-constriction are observed. Impaired breathing also occurs as was measured by Scott and Hunt [12]. Sudden death has been reported due to exposure at extremely high concentrations of gas. This is due to the rapid consumption of oxygen by nitrogen oxides resulting in less oxygen being available, with resulting hypoxia. The best treatment for the disease is prevention through education of farm workers and managers. Specifically working in silos properly ventilated, and where possible not working alone. Steroid therapy has been used to treat the disease with varying degrees of success.

However, not all of parts of the immune system may be involved. In vitro effects of nitrogen dioxide $\left(\mathrm{NaNO}_{2}\right)$ were studied in an assay which used vesicular stomatitis virus (VSV) to infect rabbit RK13 cells. Type 1 interferon (IF) produced completely inhibited virus (VSV) plaque production derived from splenic lymphocytes either treated or not treated with $\mathrm{NaNO}_{2}$ below an IF dilution of $10^{-2.5}$. At the $10^{-2.5}$ dilution of IF, plaque numbers in both treated and untreated groups were reduced $95 \%$. The $10^{-3.0}$ and $10^{-3.5}$ dilutions produced an $82 \%$ and $66 \%$ reduction respectively in plaque number. The protective effect was mediated by a reduction in the IF level, not by presence of $\mathrm{NaNO}_{2}$. These data indicate that at least for interferon (Type 1), nitrogen dioxide presence may not be a relevant factor in preventing the immune response, in this case interferon from attacking this virus. This also is an indicator of the toxic, yet selective nature of the gas in solution.

The Mayo Clinic collected patient data over a 32 year period for patients exposed to silo gas. There were 17 patients examined with acute lung injury occurring in 11 of those patients. Clinical findings included alveolar damage hemorrhagic edema [13]. Hypoxemia and airway obstruction occurred, but infiltrates were not observed. Corticosteroids were the treatment regimen in this study as was the case for other studies [3,7].

Correspondence to: Dr. C. Schultz, Department of Biology, University of Calgary, Calgary, Alberta, Canada T2N 1N4, Tel: 403.220.5278, E-mail: schultzc@ucalgary.ca

Key words: lung, farmer, disease, agriculture, inflammation, mold

Received: June 22, 2016; Accepted: June 28, 2016; Published: June 01, 2016 
Farmer's Lung is one member of a disease group known collectively as Hypersensitivity Pneumonia (HP). Other diseases included in this group are Summer-type HP, Hot Tub Lung, Pigeon Breeders disease and MDI HP [14]. Summer-type HP is a disease that occurs almost exclusively in Asia, especially Japan where it is the most common type of pneumonitis accounting for about $70 \%$ of all reported cases $[15,16]$. Specific antibody may be detected against Trichosporon asahii and Trichosporon mucoides. Interestingly, data indicate that smoking tends to suppress the disease presumably by stimulating macrophage activity in the lung and thus antigen clearance [16]. Hot Tub Lung is a more recent syndrome associated with hotels and spas [17]. Hot Tub Lung is a granulomatous disease caused by the Mycobacterium avium complex. The bacterial complex is inhaled as part of a water aerosol mixture and has recently (2016) been reported associated with a husband and wife in Japan [18]. Pigeon Breeders disease is an HP caused by the inhalation of bird derived proteins $[19,20]$. The condition may be acute, subacute or chronic. The pathology of this disease may be linked to frequency and intensity of exposure to the protein complex. CT scans show pulmonary cysts and a diffuse ground-glass appearance [19]. Patients who avoid contact with the antigen complex for a sustained period demonstrate relief from the disease. Methylene diphenyl discocyante hypersensitivity pneumonitis, (MDI HP) is chemical that following exposure can lead to a variety of symptoms. The chemical causes an allergic contact dermatitis and asthma [21,22]. This chemical is used worldwide and has the ability to penetrate into the lower lung [21]. It can penetrate protective equipment such as gloves and thus cause skin dermatitis [22].

Farmer's Lung is a hypersensitivity (pneumonitis) condition caused by inhalation of mold spores [23]. Symptoms may occur as early as 2-4 hours in the acute form after exposure and include cough, fever, chills, sweating headache and malaise. Nausea has been reported within 10 hours post-exposure. The chronic form of the disease has an onset over months with increased fatigue and weight loss. A more recent and much rarer manifestation is the presence of large bulla in the lung [24]. The disease usually manifests itself during the winter months when handling moldy organic materials. Rain during the harvest season is a major factor. Studies have linked the prevalence of the disease to weather conditions. Serological testing for the antigens is common but may not be conclusive in disease diagnosis. In the acute phase of the disease loss of lung volume is noted. Chest radiology may indicate nodular or linear shadows. In the more prolonged chronic phase of the disease, weight loss and fatigue may result. The prevalence of the disease may range from $3 \%$ to $9 \%$, and is more common in climatic conditions which may support mold growth such as increased humidity the associated dampness, especially in areas where hay is stored. Other authors put the prevalence of the disease at $0.5 \%$ to $3 \%$. A study in China among 5,880 active greenhouse farmers put the incidence at $5.8 \%$ [25].

More recently Saccharopolyspora rectivirgula and Eurotium amstelodami have been specifically identified associated with compost workers and subsequently associated with serum antibodies in the blood of these workers especially during hay making season and thus as causative agents of FL [26,27]. The genome sequence for these antigens has been shown [28].

Treatment includes avoidance of, or protection from moist hay, especially with workers previously exposed who have had an infection. Since FL often manifests itself as lung inflammation, some farmers have taken steroids proactively during hay making season to lessen or avoid the symptoms of the disease. Chief among these is prednisolone.
However, steroids have not been shown to have a beneficial effect in long term disease treatment. Work practices on farms have a major effect. The quality and moisture content of hay have a major impact on the prevalence of the disease. Warm air drying of loose hay leads to less contamination and thus less chance of exposure.

\section{Conclusion}

These two diseases have been almost endemic in the agricultural industry worldwide for centuries. Sheer speculations about the cause of these syndromes have given way to specific disease causes and genetic mapping of the etiologic agents of Farmer's Lung. While the causes of these diseases have followed the same learning trajectory as more recent syndromes of the modern age such as Zika Virus, the treatment or prevention regimens are the same. In the case of Farmer's Lung and Silo Filler's Disease, the main treatment is prevention. Specifically, avoidance of the disease causing agents.

\section{References}

1. Ramazzini B. 1713. De Morbus Artificium Diatriba. \{A Discourse on Occupational Lung Disease\}. Wright WC (translation), Chicago, IL (USA) 1940.

2. Fleetham JA, Munt PW, Tunnicliffe BW (1978) Silo-filler's disease. Can Med Assoc J 119: 482-484. [Crossref]

3. Seaton A (1984) The breathless farm worker. Br Med J (Clin Res Ed) 288: 1940-1941 [Crossref]

4. Chan-Yeung M, Ashley MJ, Grzybowski S (1978) Grain dust and the lungs. Can Med Assoc J 118: 1271-1274. [Crossref]

5. LOWRY T, SCHUMAN LM (1956) Silo-filler's disease; a syndrome caused by nitrogen dioxide. J Am Med Assoc 162: 153-160. [Crossref]

6. Moskowitz R, Lyons H, Cottle H (1964) Silo filler's disease. Clinical, physiologic and pathologic study of a patient. Am J Med 36: 457-459.

7. GRAYSON RR (1956) Silage gas poisoning: nitrogen dioxide pneumonia, a new disease in agricultural workers. Ann Intern Med 45: 393-408. [Crossref]

8. Warren C (1977) Lung disease in farmers. CMA Journal 116: 391-394.

9. Verhoeff J, Counotte G, Hamhuis D (2007) Nitrogen dioxide (silo gas) poisoning in dairy cattle. Tijdschr Diergeneeskd 132: 780-782. [Crossref]

10. do Pico GA (1996) Lung (agricultural/rural). Otolaryngol Head Neck Surg 114: 212 216. [Crossref]

11. Gurney JW, Unger JM, Dorby CA, Mitby JK, Von Essen SG (1991) Agricultural disorders of the lung. Radiographics 11: 625-634. [Crossref]

12. Scott EG, Hunt WB Jr (1973) Silo filler's disease. Chest 63: 701-706. [Crossref]

13. Douglas WW, Hepper NG, Colby TV (1989) Silo-filler's disease. Mayo Clin Proc 64: 291-304. [Crossref]

14. Lacasse Y, Cormier Y (2006) Hypersensitivity pneumonitis. Orphanet J Rare Dis 1: 25. [Crossref]

15. Inase N, Ohatani Y, Usui Y, Miyazaki Y (2007) Chronic summer-type hypersensitivity pneumonitis: clinical similarities to idiopathic pulmonary fibrosis. Sarcoidosis Vasc Diffuse Lung Dis 24: 141-147. [Crossref]

16. Asai N, Kaneko N, Ohkuni Y, Aoshima M, Kawamura Y (2016) Familial Summer-type Hypersensitivity Pneumonitis: A Review of 25 Families and 50 Cases in Japan. Intern Med 55: 279-283. [Crossref]

17. Fjällbrant H, Akerstrom M, Svensson E, Andersson E (2013) Hot tub lung: an occupational hazard. Eur Respir Rev 22: 88-90. [Crossref]

18. Kitahara Y, Araki Y, Nakano K (2016) A case of familial hot tub lung. Respir Med Case Rep 17: 71-74. [Crossref]

19. Hoshi S, Tamura A, Sasaki O, Kato A, Nakayama Y, et al. (2007) [Case of chronic pigeon breeder's disease accompanied by pulmonary cysts]. Nihon Kokyuki Gakkai Zasshi 45: 766-771. [Crossref]

20. Gaxiola M, Buendía-Roldán I, Mejía M, Carrillo G, Estrada A, et al. (2011) Morphologic diversity of chronic pigeon breeder's disease: clinical features and survival. Respir Med 105: 608-614. [Crossref] 
21. Wisnewski AV, Liu J (2016) Immunochemical detection of the occupational allergen, methylene diphenyl diisocyanate (MDI), in situ. J Immunol Methods 429: 60-65. [Crossref]

22. Henricks-Eckerman M and Makela E (2015) A new penetration test method: protection efficiency of glove and clothing materials against Diphenylmethane diisocyanate (MDI). Ann Occup Hyg 59: 221-231. [Crossref]

23. Cano-Jiménez E, Acuña A, Botana MI, Hermida T, González MG, et al. (2016) Farmer's Lung Disease. A Review. Arch Bronconeumol 52: 321-328. [Crossref]

24. Koschel D, Holfert J, Rolle A, Holotiuk O, Höffken G (2012) Farmer's lung in a case after bullectomy. Int Arch Allergy Immunol 158: 313-316. [Crossref]

25. Liu S, Chen D, Fu S, Ren Y, Wang L, et al. (2015) Prevalence and risk factors for farmer's lung in greenhouse farmers: an epidemiological study of 5,880 farmers from Northeast China. Cell Biochem Biophys 71: 1051-1057. [Crossref]

26. Schäfer J, Klug K, van Kampen V, Jäckel U (2013) Quantification of Saccharopolyspora rectivirgula in composting plants: assessment of the relevance of S. rectivirgula. Ann Occup Hyg 57: 875-883. [Crossref]

27. Roussel S, Reboux G, Rognon B, Monod M, Grenouillet F, et al. (2009) Comparison of three antigenic extracts of Eurofilm amstelodami in serological diagnosis of Farmer's Lung Disease. Clin Vaccine Immunol 17: 160-67.

28. Barrera C, Valot B, Rognon B, Zaugg C, Manod M, et al. (2014) Draft genome sequence of the principle etiological agent of Farmer's Lung Disease, Saccaropolyspora rectivirgula. Genome Announc 2: e01340-14.

Copyright: $\odot 2016$ Schultz C. This is an open-access article distributed under the terms of the Creative Commons Attribution License, which permits unrestricted use, distribution, and reproduction in any medium, provided the original author and source are credited. 